\title{
Editorial: Invaders on the Horizon! Scanning the Future of Invasion Science and Management
}

\author{
Ana Sofia Vaz ${ }^{1 *}$, Ana Novoa ${ }^{2}$, Joana R. Vicente ${ }^{1}$, João P. Honrado ${ }^{1,3}$ and \\ Ross T. Shackleton ${ }^{4,5}$ \\ ${ }^{1}$ Research Network in Biodiversity and Evolutionary Biology, Research Centre in Biodiversity and Genetic Resources \\ (InBIO-CIBIO), Vila Do Conde, Portugal, ${ }^{2}$ Department of Invasion Ecology, Institute of Botany, Czech Academy of Sciences, \\ Pruhonice, Czechia, ${ }^{3}$ Faculty of Sciences, University of Porto, Rua Do Campo Alegre, Porto, Portugal, ${ }^{4}$ Institute of \\ Geography and Sustainability, University of Lausanne, Lausanne, Switzerland, ${ }^{5}$ Department of Botany and Zoology, Centre \\ for Invasion Biology, Stellenbosch University, Stellenbosch, South Africa
}

Keywords: biological invasions, emerging issues, horizon scan, multidisciplinary, technology

\section{Editorial on the Research Topic}

Invaders on the Horizon! Scanning the Future of Invasion Science and Management

OPEN ACCESS

Edited and reviewed by: Peter Convey,

British Antarctic Survey (BAS), United Kingdom

${ }^{*}$ Correspondence: Ana Sofia Vaz

sofia.linovaz@gmail.com

Specialty section:

This article was submitted to Biogeography and Macroecology,

a section of the journal

Frontiers in Ecology and Evolution

Received: 10 August 2021

Accepted: 30 August 2021

Published: 27 September 2021

Citation:

Vaz AS, Novoa A, Vicente JR,

Honrado JP and Shackleton RT (2021) Editorial: Invaders on the

Horizon! Scanning the Future of

Invasion Science and Management.

Front. Ecol. Evol. 9:756339.

doi: 10.3389/fevo.2021.756339

\section{INTRODUCTION}

In the current era of dynamic human-environment interactions, the phenomenon of biological invasions is a key fingerprint of the Anthropocene (IPBES, 2019). Alongside a changing climate and an increasingly connected world, the rate and number of introduced species, and particularly of established invasive species, is predicted to increase (Seebens et al., 2017). Invasive species are organisms that are introduced (intentionally or accidentally) by humans into regions beyond their natural distributions, where they spread rapidly, representing a major driver of biodiversity and ecosystem change (Stoett et al., 2019), and impact on human welfare, culture, health, and economies (Simberloff et al., 2013).

Anticipating future challenges and opportunities is paramount for adequate strategy development, policy making, risk management, threat identification, and research prioritization in invasion science (Ricciardi et al., 2017). Several studies have been conducted to anticipate future invasion processes and their risks (e.g., Gallardo et al., 2016; Roy et al., 2019; Hughes et al., 2020; Lucy et al., 2020), and thereby pinpoint future monitoring and management measures toward invasive species (e.g., Matlack, 2002; Robertson et al., 2003; Booy et al., 2020).

To effectively anticipate invasions and be prepared for the challenges ahead, some priority issues have been proposed for fostering progress and adjusting the course of invasion research and management (e.g., Caffrey et al., 2014; Ricciardi et al., 2017; Dehnen-Schmutz et al., 2018). Among the proposed priority issues are the development of new technologies to tackle invasive species, the improvement of ecological prediction and knowledge on invasion risks, and the consideration of socio-economic factors in invasion research and management. This Research Topic includes 15 papers exploring these three broad issues, and draws on research papers, reviews and case studies that aim to contribute to advance the way biological invasions can be studied and managed. 


\section{TACKLING INVASIONS WITH NEW TECHNOLOGIES}

A set of papers in this Research Topic focus on technological advancements within the fields of genetics, remote sensing, and electric barriers to help with the management of invasive species. Resh et al. show the usefulness of whole genome scanning to determine the source of introduction of invasive species. Using the introduction of the invasive fish Channa argus in the United States of America from China as case study, they show how detailed information from whole genome scanning can support the development of targeted strategies to regulate established populations and inhibit further spread. Datta et al. discuss the latest developments of satellite remote sensing and machine learning technologies to improve our capacity to monitor the invasive plant Eichhornia crassipes within freshwaters systems. Egly et al. test the efficiency of electric barriers, a potential new technology to manage invasive species, for two invasive invertebrates, Procambarus clarkii and Hyalella azteca, showing that although the barriers may not slow or prevent spread of invasive invertebrates when attached to water vehicles, they can be useful to prevent the spread of these species through active upstream movement.

\section{IMPROVING ECOLOGICAL PREDICTION AND KNOWLEDGE}

Several papers focus on making predictive ecology more relevant to decision makers. Dinis et al. advance the application of species distribution models to predict the success of the Australian gallforming wasp, Trichilogaster acaciaelongifoliae, as a biocontrol agent for the invasive tree Acacia longifolia in Portugal, serving as a framework for similar biocontrol programs in other regions worldwide. Morais et al. use a system dynamic modeling approach to find the cost-effectiveness optimum of control actions toward the invasive shrub Hakea sericea under wildfire risk scenarios. Finally, Holenstein et al. model the distribution of 1,602 non-native species in the vicinity of 671 protected areas through time in Norway, highlighting that management efforts should extend beyond the interior of protected areas.

Other papers focus on challenging different hypotheses underlying the invasion process. Using an experimental design in grasslands with the invasive species Ambrosia artemisiifolia and Solidago gigantea, Yannelli et al. show no evidence to support a limiting similarity effect. Instead, the authors suggest that native communities more effectively suppress invaders that arrived after the natives. Similarly, native communities that produce the most biomass suppress invaders more effectively than native communities that share similar traits with these invaders. Through a multi-species greenhouse experiment with 10 alien invasive plant species in China, Gao et al. find no support for the idea that soil nutrient heterogeneity favors the invasion success of exotic plant species in native plant communities. Other ecological issues pertaining to invasive species, and particularly marine invasions, are also represented in this Research Topic, namely through a review on the potential role of plastic debris as vectors for the introduction of invasive species (García-Gómez, Garrigós et al.), and the observation of rapid invasion processes and impacts caused by the alga Rugulopteryx okamurae in Mediterranean and Atlantic waters (García-Gómez, Florido, Olaya-Ponzone, Sempere-Valverde et al.; García-Gómez, Florido, García-Gómez, Florido, de Rada et al.).

\section{INCLUDING SOCIO-ECONOMIC FACTORS IN INVASION MANAGEMENT}

The remaining set of papers presented in this Research Topic focus on the identification of priority invasive species that pose socio-economic risks and impacts. Peyton et al. undertake horizon scanning using expert-elicitation to predict arrivals of invasive alien species that could have adverse human health or economic impacts on the island of Cyprus, and from there, to inform biosecurity policies and communication around invasive species. Likewise, Lenzner et al. conduct a survey among 126 experts in invasion science, suggesting an increasing trend in the spread and establishment of alien species in island systems associated to socio-economic activities and human mediated pathways. Goldsmit et al. adopt a screening assessment tool to identify invasive species of highrisk environmental and economic impacts in Canada, supporting the creation of watch lists to inform adaptive management for preventing the establishment of invaders. Finally, grounded on historical records and paleoenvironmental reconstructions, Costa et al. highlight how trends in international trade, importation of goods, and enhanced connectivity by increasing flights and shipping will probably promote the arrival and spread of several new non-indigenous freshwater species in the Azores archipelago.

\section{CONCLUDING NOTE}

There are no expectations that invasive species will pose fewer challenges in the future. In fact, most predictions suggest the opposite (Seebens et al., 2017), in particular when coupled with other global change drivers like climate change. In order to understand the true complexity of invasion processes and to know how to manage invasive species, it is clear that a multidisciplinary and collaborative approach is needed. A diversity of perspectives grounded on better ecological knowledge, inclusion of socio-economic perspectives and adoption of reliable technologies can elucidate the challenges of invasion science, as well as offer new and more effective ways to manage invasive species and mitigate their impacts. This Research Topic has highlighted the opportunities that the rapidly expanding fields of remote sensing, electric barriers, and genetics bring to the understanding, surveillance, and control of invasions. It has further challenged existing hypotheses and explored new ones to improve knowledge on fast invasions and their interactions with native biota. Additionally, it has emphasized the importance of socio-economic factors in invasion management, namely through the role of humans as vectors of invasions and receivers of their impacts. In a 
constantly changing world and with rapid advances in science and technology, scanning the future of invasion science may be challenging, yet is imperative to adjust the course of invasion research and management.

\section{AUTHOR CONTRIBUTIONS}

$\mathrm{AV}, \mathrm{AN}, \mathrm{JV}, \mathrm{JH}$, and RS jointly wrote and edited the article. All authors contributed to the article and approved the submitted version.

\section{REFERENCES}

Booy, O., Robertson, P. A., Moore, N., Ward, J., Roy, H. E., Adriaens, T., et al. (2020). Using structured eradication feasibility assessment to prioritize the management of new and emerging invasive alien species in Europe. Global Change Biol. 26, 6235-6250. doi: 10.1111/gcb.15280

Caffrey, J. M., Baars, J.-R., Barbour, J. H., Boets, P., Boon, P., Davenport, K., et al. (2014). Tackling invasive alien species in Europe: the top 20 issues. Manage. Biol. Invasions 5, 1-20. doi: 10.3391/mbi.2014.5.1.01

Dehnen-Schmutz, K., Boivin, T., Essl, F., Groom, Q. J., Harrison, L., Touza, J. M., et al. (2018). Alien futures: what is on the horizon for biological invasions? Diversity Distributions 24, 1149-1157. doi: 10.1111/ddi.12755

Gallardo, B., Zieritz, A., Adriaens, T., Bellard, C., Boets, P., Britton, J. R., et al. (2016). Trans-national horizon scanning for invasive nonnative species: a case study in western Europe. Biol. Invasions 18, 17-30. doi: 10.1007/s10530-015-0986-0

Hughes, A. C., Lechner, A. M., Chitov, A., Horstmann, A., Hinsley, A., Tritto, A., et al. (2020). Horizon scan of the belt and road initiative. Trends Ecol. Evolution 35, 583-593. doi: 10.1016/j.tree.2020.02.005

IPBES (2019). Summary for Policymakers of the Global Assessment Report on Biodiversity and Ecosystem Services of the Intergovernmental SciencePolicy Platform on Biodiversity and Ecosystem Services (IPBES). Bonn: IPBES Secretariat.

Lucy, F. E., Davis, E., Anderson, R., Booy, O., Bradley, K., Britton, J. R., et al. (2020). Horizon scan of invasive alien species for the island of Ireland. Manage. Biol. Invasions 11, 155-177. doi: 10.3391/mbi.2020.1 1.2 .01

Matlack, G. R. (2002). Exotic plant species in Mississippi, USA: critical issues in management and research. Natural Areas J. 3, 241-247.

Ricciardi, A., Blackburn, T. M., Carlton, J. T., Dick, J. T. A., Hulme, P. E., Iacarella, J. C., et al. (2017). Invasion science: a horizon scan of emerging challenges and opportunities. Trends Ecol. Evol. 32, 464-474. doi: 10.1016/j.tree.2017.03.007

Robertson, M. P., Villet, M. H., Fairbanks, D. H. K., Henderson, L., Higgins, S. I., Hoffmann, J. H., et al. (2003). A Proposed Prioritization System for the

\section{FUNDING}

The authors acknowledge support from the Ministerio de Ciencia, Innovación y Universidades in Spain [contract reference FJC2018-038131-I], the Portuguese Foundation for Science and Technology [contract references DL57/2016/ICETA/EEC2018/13 and 2020.01175.CEECIND], the Czech Science Foundation [EXPRO grant no. 19-28807X], and the Czech Academy of Sciences [long-term research development project RVO 67985939].

Management of Invasive Alien Plants in South Africa. Available online at: http:// hdl.handle.net/11427/27322

Roy, H. E., Bacher, S., Essl, F., Adriaens, T., Aldridge, D. C., Bishop, J. D. D., et al. (2019). Developing a list of invasive alien species likely to threaten biodiversity and ecosystems in the European Union. Global Change Biol. 25, 1032-1048. doi: $10.1111 /$ gcb.14527

Seebens, H., Blackburn, T. M., Dyer, E. E., Genovesi, P., Hulme, P. E., Jeschke, J. M., et al. (2017). No saturation in the accumulation of alien species worldwide. Nat. Commun. 8:14435. doi: 10.1038/ncomms14435

Simberloff, D., Martin, J.-L., Genovesi, P., Maris, V., Wardle, D. A., Aronson, J., et al. (2013). Impacts of biological invasions: what's what and the way forward. Trends Ecol. Evol. 28, 58-66. doi: 10.1016/j.tree.2012.07.013

Stoett, P., Roy, H. E., and Pauchard, A. (2019). Invasive alien species and planetary and global health policy. Lancet Planetary Health 3, e400-e401. doi: 10.1016/S2542-5196(19)30194-9

Conflict of Interest: The authors declare that the research was conducted in the absence of any commercial or financial relationships that could be construed as a potential conflict of interest.

Publisher's Note: All claims expressed in this article are solely those of the authors and do not necessarily represent those of their affiliated organizations, or those of the publisher, the editors and the reviewers. Any product that may be evaluated in this article, or claim that may be made by its manufacturer, is not guaranteed or endorsed by the publisher.

Copyright (C) 2021 Vaz, Novoa, Vicente, Honrado and Shackleton. This is an openaccess article distributed under the terms of the Creative Commons Attribution License (CC BY). The use, distribution or reproduction in other forums is permitted, provided the original author(s) and the copyright owner(s) are credited and that the original publication in this journal is cited, in accordance with accepted academic practice. No use, distribution or reproduction is permitted which does not comply with these terms. 